CAPÍTULO 12

\title{
TERRITÓRIO, CONFLITOS E INSTRUMENTOS DE POLÍTICA AMBIENTAL: DAS ÁREAS DE PROTEÇÃO AMBIENTAL AO PROJETO DO PARQUE ESTADUAL DA SERRA DO JAPI
}

DOI: http://dx.doi.org/10.18616/planar12

Ricardo Silveira Orlando 


\section{INTRODUÇÃO: AS UNIDADES DE CONSERVAÇÃO NA POLÍTICA AMBIENTAL BRASILEIRA}

É crescente nas ciências humanas o interesse pelo estudo das unidades de conservação sob a ótica da política ambiental participativa e o ativismo dos movimentos sociais rurais e urbanos. Neder (2002) e Ferreira e Salles (2016), por exemplo, são autores que se dedicam à análise da construção do aparato técnico-legal e a incongruente regulação pública governamental no campo das políticas ambientais na história do Estado brasileiro. Neder (2002), por exemplo, procura demonstrar os três tipos de intervenções relacionadas à questão socioambiental no Brasil nas últimas décadas: 1) a proteção de ecossistemas brasileiros por meio das unidades de conservação; 2) a política de zoneamento e controle ambiental com ênfase punitivo-pedagógica de multas e advertências promovidas pelos órgãos de controle ambientais estatais; 3) o debate ambiental sobre a sustentabilidade (e suas múltiplas dimensões).

Neder (2002) adverte que a década de 1930 foi marcada pela constituição dos marcos regulatórios sobre os recursos naturais brasileiros. Nesse contexto, a questão ambiental passou a ser definida pelo controle do Estado com a criação de órgãos e legislações federais que arbitraram sobre assuntos como a pesca, água, energia elétrica, minérios, florestas e parques nacionais.

A regulação estatal tinha como objetivo o controle dos recursos naturais a fim de disponibilizá-los para uma incipiente industrialização. Assim, foram construídas com capitais estatais, siderurgias, indústrias petroquímicas e empresas de extração mineral. Indústrias como a Companhia Siderúrgica Nacional (1942) e a Petrobrás (1953) tiveram um papel de destaque na criação das bases do capitalismo industrial brasileiro.

Em relação à política de áreas protegidas, Bensusan (2006) considera que coube ao Código Florestal (1934) introduzir na legislação a figura de unidade de conservação, subdividindo-a em quatro classificações: florestas protetoras, florestas remanescentes, florestas modelo e florestas de rendimento. 
Ainda conforme a autora, a nova versão do Código Florestal (1965) definiu os parques nacionais como as áreas criadas com a finalidade de resguardar atributos excepcionais da natureza, conciliando a proteção integral da flora, da fauna e das belezas naturais com a utilização para objetivos educacionais, recreativos e científicos.

Acselrad (2001) nos alerta que, apesar da emergência de novas legislações no campo da área ambiental, os primeiros passos dados em relação aos espaços ambientalmente protegidos evidenciavam a posição contraditória do Estado brasileiro. Ao mesmo tempo em as autoridades políticas assumiam um discurso conservacionista diante da diplomacia internacional, não conseguiam (ou não tinham interesse) evitar a atuação dos grandes fazendeiros e madeireiros. Ao contrário, esses grupos econômicos recebiam vultosos subsídios estatais para o avanço das fronteiras agrícolas em direção à Amazônia.

A década de 1980 é marcada pelo processo de redemocratização das instituições brasileiras e a da revitalização dos movimentos sociais rurais e urbanos no país que corroboraram para uma nova concepção de gestão pública e de planejamento do território com base na participação social de agentes anteriormente excluídos. É nesse sentido que o tripé democracia - ambiente inclusão social vai ocupar um espaço privilegiado na agenda pública brasileira, principalmente nos anos de 1990.

É diante dessa nova atmosfera política que ocorre a promulgação da Constituição Federal (1988), que em seu trecho que trata da questão ambiental, é um forte indicador dos novos ativismos ambientais. O artigo 225 reforça que todos "(...) têm o direito ao meio ambiente ecologicamente equilibrado, bem de uso comum do povo e essencial e à sadia qualidade de vida, impondo-se ao poder público e à coletividade o dever de defendê-lo e preservá-lo para as presentes e futuras gerações."

Assim, ao conclamar a coletividade para defesa e preservação do meio ambiente, insere em legislações posteriores, a participação popular como condição para o bom funcionamento das novas estruturas institucionais (áreas protegidas, conselhos, colegiados, conferências dentre outros). Nesse 
caminho, também caberia ao poder público (municipal, estadual ou federal) “(...) definir, em todas as Unidades da Federação, espaços territoriais e seus componentes a serem especialmente protegidos (...).”

Foi com essa base constitucional que o Brasil concebeu o seu Sistema Nacional de Unidades de Conservação (SNUC). O processo que culminou entre a aprovação do anteprojeto pelo Conselho Nacional de Meio Ambiente (CONAMA) em 1992 e a assinatura da lei em 2000 suscitou um embate entre as diferentes correntes do movimento ambientalista brasileiro, ruralistas e garimpeiros.

O anteprojeto foi aprovado pelo Conselho do Meio Ambiente (CONAMA) e em maio de 1992, já na qualidade de projeto de lei, foi encaminhado ao Congresso Nacional. Em 1994, o deputado Fábio Feldmann apresentou um substitutivo ao projeto de lei do SNUC, introduzindo mudanças significativas no texto original e dando início à polêmica centrada na questão da presença de populações tradicionais nas unidades de conservação (...). Em 1995, novo substitutivo foi apresentado, desta vez pelo deputado Fernando Gabeira, aprofundando as divergências entre os ambientalistas e alimentando, ainda mais, a polêmica. Após inúmeras reuniões, audiências públicas, versões e modificações, o projeto foi aprovado no Congresso em 2000, mas teve ainda alguns dispositivos vetados pelo presidente, como, por exemplo, a definição de populações tradicionais. (BENSUSAN, 2006: 20)

Apesar das históricas ambiguidades (e conflitos) no campo da política ambiental brasileira, finalmente em julho de 2000 é aprovado o Sistema Nacional de Unidades de Conservação. A legislação do SNUC agrupou as diferentes tipologias de unidades de conservação em duas grandes categorias: as Unidades de Proteção Integral e a Unidades de Uso Sustentável.

Acompanhando a tendência de incluir processos participativos na gestão e planejamento territorial, o SNUC estipulou que as unidades de con- 
servação (sejam elas de proteção integral ou de uso sustentável) deveriam possuir conselhos gestores com a participação de representantes da sociedade civil (notadamente as comunidades inseridas ou residentes no entorno das áreas protegidas) e do Estado. Entre as funções dessas estruturas colegiadas, destacamos a elaboração de um plano de manejo (elaborado até os primeiros cinco anos de existência da unidade de conservação) e o zoneamento do território.

No SNUC o zoneamento é definido como:

(...) a definição de setores ou zonas em uma unidade de conservação com objetivos de manejo e normas específicas, com o propósito de proporcionar os meios e as condições para que todos os objetivos da unidade possam ser alcançados de forma harmônica e eficaz.

O zoneamento territorial nas unidades de uso sustentável deve incorporar a participação das comunidades locais nos processos decisórios e garantir a conservação ambiental e o bem-estar das populações humanas. Nessas situações o território é objeto de disputas entre diferentes atores sociais em arenas de grande complexidade. Assim, temos que considerar que a participação, tão debatida em círculos acadêmicos e exigida pela legislação, possa não se concretizar de forma esperada. Passadas duas décadas da aprovação do SNUC, é notável as dificuldades encontradas pela sociedade no interior dos conselhos gestores, dadas as diferenças sociais, culturais e econômicas entre os participantes.

\section{A FIGURA INSTITUCIONAL DAS ÁREAS DE PROTEÇÃO AMBIENTAL NO BRASIL}

A Área de Proteção Ambiental (APA) e a Estação Ecológica (ESEC) foram instituídas através da lei federal n. 6.902, de 27 de abril de 1981, antes mesmo da aprovação da Política Nacional do Meio Ambiente (PNMA). 
Conforme os dispositivos da lei, nas Estações Ecológicas ficaram proibidas as atividades econômicas, exceto aquelas vinculadas diretamente à educação e pesquisa. Já no primeiro artigo da lei, o caráter preservacionista (proteção integral) fica explícito ao se afirmar que as Estações Ecológicas “(...) são áreas representativas dos ecossistemas brasileiros, destinadas à realização de pesquisas básicas e aplicadas de Ecologia, à proteção do ambiente natural e ao desenvolvimento da educação conservacionista”.

As Áreas de Proteção Ambiental (APAs), entretanto, adquiririam outra natureza institucional. No artigo 80 da lei afirmou-se que o poder executivo, “(...) quando houver relevante interesse público, poderá declarar determinadas áreas do Território Nacional como o de interesse para a proteção ambiental, a fim de assegurar o bem-estar das populações humanas e conservar ou melhorar as condições ecológicas locais".

Dessa forma, as APAs garantiram os princípios de propriedade presentes no direito constitucional. Entretanto, no território de uma APA, o poder público tem a liberdade de estabelecer normas, limitar ou proibir atividades humanas que causem impactos ambientais.

Na RESOLUÇÃO CONAMA n. 10/88, as APAs foram conceituadas como "Unidades de Conservação, destinadas a proteger e conservar a qualidade ambiental e os sistemas naturais existentes, visando à melhoria da qualidade de vida da população local e também a proteção de ecossistemas regionais." De acordo com o art. $2^{\circ}$, as APAs deverão apresentar um zoneamento ambiental que seja capaz de estabelecer normas de uso, considerando as condições bióticas, geológicas, urbanísticas, agropastoris, extrativistas, culturais, dentre outras.

A resolução também definiu diferentes zonas e usos: Zona de Usos Especiais (quando houver na área detectada outra unidade de conservação ou mecanismo de proteção); Zonas de Vida de Silvestre (Zona de Preservação de Vida Silvestre ou Zona de Conservação da Vida Silvestre); Zona de Uso Agropecuário e Zona de Urbanização.

Apesar do avanço conceitual trazido pelo Conama, a definição atual do que vem a ser uma APA ocorreu com a aprovação da lei n. 9.985, de 18 de 
julho de 2000, que instituiu o Sistema Nacional de Unidades de Conservação. A Área de Proteção Ambiental, constituinte do grupo das Unidades de Uso Sustentável, foi definida no artigo 15 como:

(...) uma área em geral extensa, com certo grau de ocupação humana, dotada de atributos abióticos, bióticos e estéticos ou culturais especialmente importantes para a qualidade de vida e o bem-estar das populações humanas, e tem como objetivos básicos proteger a diversidade biológica, disciplinar o processo de ocupação e assegurar a sustentabilidade dos recursos naturais.

Na nova redação dada pelo SNUC, as APAs podem existir em terras públicas ou privadas desde que sejam respeitados os limites constitucionais na aplicação de normas e regras. De certa maneira, as APAs supriram algumas expectativas ambientalistas, notadamente da corrente socioambientalista, com relação ao desenvolvimento sustentado em áreas particulares. A lógica de operacionalidade das APAs prevê políticas restritivas (inclusive em relação ao uso do solo) e a manutenção da estrutura fundiária local sem a necessidade de desapropriação (que, na maioria das vezes, é um processo lento e oneroso). Portanto, o desafio de uma APA é se transformar em um instrumento para o desenvolvimento de políticas que estimulem a conservação da diversidade biológica e dos recursos naturais com o uso sustentável nas terras, as quais, geralmente, são de propriedade privada.

Nas áreas de domínio público, as condições para pesquisa científica e visitação são estabelecidas pelo órgão gestor da unidade. Já nas áreas de domínio privado cabe ao proprietário praticar tais regulações.

Na legislação do SNUC os conselhos gestores de APAs se tornaram arenas (deliberativas e consultivas) de participação dos agentes sociais e econômicos com diferentes perspectivas em relação ao uso do território (conflitos). $\mathrm{O}$ artigo 15 afirma que: 
A Área de Proteção Ambiental disporá de um Conselho presidido pelo órgão responsável por sua administração e constituído por representantes dos órgãos públicos, de organizações da sociedade civil e da população residente, conforme se dispuser no regulamento desta lei.

Ao longo da afirmação jurídico-institucional da Área de Proteção Ambiental - enquanto instrumento de política ambiental - houve uma divisão entre os setores do ambientalismo brasileiro. Para os conservacionistas (socioambientalistas), a figura da APA tornou-se um espaço privilegiado e desafiador ao se buscar a conservação da biodiversidade e de outros recursos naturais e a inclusão (política, econômica e social) de populações locais. Já para os preservacionistas, a APA é muitas vezes sinônimo de ineficiência e desrespeito à gestão ambiental e planejamento do território.

Nessa linha, Bensusan (2006:35) afirma que:

Algumas unidades, como as áreas de proteção ambiental (APAs) não possuem boa reputação como importantes para a conservação da biodiversidade; essa má fama, entretanto, está mais relacionada ao seu baixo grau de implantação e, consequentemente, à sua ineficiência, do que com as diretrizes teóricas que regem essa modalidade de área protegida. Ou seja, há inúmeras 'APAs de papel'. Outras também apresentam problemas similares (...). (BENSUSAN, 2006: 35)

Drummond, Franco e Oliveira (2010) apontam que a pressão internacional sobre o país a partir da década de 1970 levou o Estado brasileiro a uma política ambiental que privilegiava as áreas de proteção integral. Todavia, uma mudança mundial de concepção de áreas protegidas priorizou não somente a conservação da biodiversidade bem como o uso sustentável dos recursos naturais. Para o autor, tais paradigmas exigiram flexibilidade nas categorias de unidades de conservação, inclusive no Brasil. Na década de 1980 observou-se 
uma forte tendência na política ambiental brasileira de valorização das áreas de conservação e uso sustentável, notadamente a categoria das APAs.

Ainda de acordo com Drummond, Franco e Oliveira (2010), existe entre os órgãos ambientais estaduais uma clara preferência pela criação de APAs, principalmente porque elas não exigem desapropriações e podem se constituir em boas ferramentas de planejamento local integrado.

Medeiros (2006) aponta que a Secretaria Especial do Meio Ambiente (1973), nascida sob o impacto dos debates da Conferência de Estocolmo, tinha entre seus objetivos a conservação do meio ambiente e o uso dos recursos naturais. No entanto, passou a exercer com o Instituto Brasileiro de Desenvolvimento Florestal (IBDF) uma confusa responsabilidade pela gestão e fiscalização da política brasileira para áreas protegidas. Na criação da SEMA esperava-se que esta fosse acumular todas as funções de gestão de áreas protegidas, restando ao IBDF a responsabilidade de fomento ao desenvolvimento da economia florestal. Não foi o que ocorreu, sendo que a SEMA estabeleceu um programa próprio de áreas protegidas que ficariam a ela subordinadas.

Ainda de acordo com o autor, a justificativa principal para a instituição dessas novas tipologias era o preenchimento de lacunas evidentes no modelo brasileiro de criação de áreas protegidas. Assim, a instituição das APAs visava estabelecer um modelo de proteção que resguardasse áreas com certo nível de ocupação, sobretudo em áreas urbanas, sem a necessidade do poder público adquirir essas terras.

\section{A SERRA DO JAPI COMO OÁSIS DA BIODIVERSIDADE: ESPAÇO INDUSTRIAL EM EXPANSÃO E ESTARATÉGIAS DE PLANEJAMENTO AMBIENTAL E TERRITORIAL}

O maciço montanhoso do Japi, com aproximadamente $350 \mathrm{Km}^{2}$ de área, está localizado nas Áreas de Proteção Ambiental Cabreúva, Cajamar e Jundiaí (APAs CCJ) e se distribui pelos munícipios de Jundiaí, Cabreúva, 
Cajamar e Pirapora de Bom Jesus. O Japi é um dos últimos remanescentes de Mata Atlântica ainda preservados no Estado de São Paulo. A exuberante vegetação resulta do encontro entre a Floresta Atlântica e as Matas de Planalto, servindo como um importante "cinturão verde" entre as regiões metropolitanas de Campinas e de São Paulo.

A biodiversidade “(...) está diretamente relacionada ao fato de que a Serra do Japi possui uma condição climática diferenciada já que se localiza em uma região ecotonal, isto é, uma área de transição ou junção entre duas ou mais formações florestais. No caso, as Umbrófilas da Serra do Mar e as Semideciduais do interior paulista”.

Fotos 1 e 2 - Recursos Hídricos e Vegetação na Serra do Japi
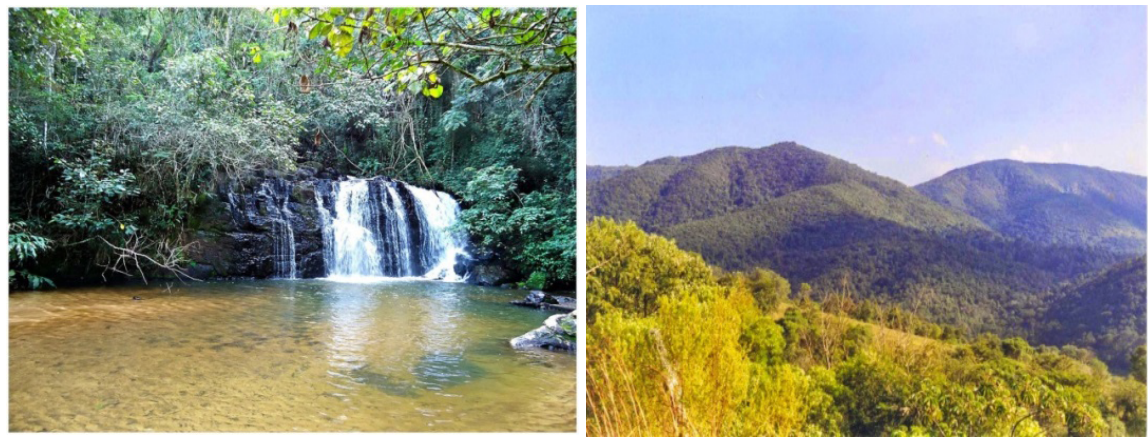

Fonte: arquivo do autor, 2016.

Do ponto de vista geofísico, a serra se transformou em uma barreira aos ventos que sopram do Oceano Atlântico em direção ao planalto paulista, possibilitando uma significativa precipitação pluviométrica. Por conta desse fenômeno, formaram-se centenas de córregos e riachos que vertem das encostas acidentadas das serras, produzindo, conforme denominação de Ab'Sáber, um "castelo de águas" útil ao abastecimento público. O próprio nome da serra, Japi, deriva do tupi-guarani y-api, que quer dizer "nascente de rios". A água 
cristalina brota das nascentes, desce pelas cachoeiras e segue cortando o relevo em meio a uma floresta bastante diversificada.

Na Serra do Japi encontramos a única floresta tropical do mundo em solos quartzitos (rochosos e ácidos). E apesar da predominância de espécies semideciduais (folhas que caem entre o outono e inverno), os tipos de vegetação variam conforme a altitude e composição dos solos.

Por causa de suas características naturais e de sua localização entre regiões muito industrializadas e urbanizadas, a Serra do Japi (e seu entorno) é palco de conflitos socioambientais. Como bem demonstra Acselrad (2004), um conflito ambiental começa a existir quando duas ou mais partes, em suas relações de sociabilidade, apresentam profunda falta de entendimento acerca de determinado tema. Os rios da Amazônia, por exemplo, não apresentam o mesmo significado social para as comunidades indígenas ou ribeirinhas como para as empresas geradoras de hidroeletricidade.

A especulação imobiliária, a expansão urbana desordenada, o crescimento industrial, o comprometimento de mananciais e a mineração são os principais problemas regionais e que pressionam a conservação da serra.

Existe um entendimento de que os instrumentos das APAs não foram suficientes para evitar a degradação da Serra do Japi, sendo necessários outros arranjos legais e jurídicos que disciplinem o planejamento ambiental e territorial. Diante de tais perspectivas, em agosto de 2009 passou a tramitar na Assembleia Legislativa de São Paulo (ALESP) o projeto de lei n. 652 cujo objetivo é transformar a área tombada da serra em um parque estadual. Após a aprovação em três comissões da Assembleia Legislativa, o projeto de lei está bem próximo de ser aprovado já que a próxima tramitação é conclusiva. 
Quadro 1 - Comparação entre APA e PE no Sistema Nacional de Unidades de Conservação

\begin{tabular}{|c|c|c|c|c|c|c|c|c|c|c|c|c|c|c|}
\hline \multirow{2}{*}{ Universidade de Conservação (UC) } & \multicolumn{3}{|c|}{ Posse e Domínio } & \multicolumn{11}{|c|}{ Atividades Possíveis na UC } \\
\hline & 2 & 3 & 4 & 1 & 2 & 3 & 4 & 5 & 6 & \begin{tabular}{l|l|}
7 & 8 \\
\end{tabular} & 9 & 10 & 11 & 12 \\
\hline \multicolumn{15}{|l|}{ I - Unidades de Proteção Integral } \\
\hline parque Estadual (PE) & $\mathrm{X}$ & & & $\mathrm{X}$ & $\mathrm{X}$ & & $\mathrm{X}$ & $\mathrm{X}$ & & \begin{tabular}{l|l}
$X$ & $X$ \\
\end{tabular} & & & & \\
\hline \multicolumn{15}{|l|}{ II - Unidades de Uso Sustentável } \\
\hline & & $\mathrm{X}$ & & $\mathrm{X}$ & $\mathrm{X}$ & & $\mathrm{X}$ & $\mathrm{X}$ & $\mathrm{X}$ & \begin{tabular}{l|l}
$X$ & $X$ \\
\end{tabular} & & $\mathrm{X}$ & & $\mathrm{X}$ \\
\hline \multicolumn{2}{|c|}{$\begin{array}{l}\text { Posse e Domínio } \\
\text { 1. Público } \\
\text { 2. Público ou privado, quando for possível } \\
\text { conciliar os objetivos da Unidade com a uti- } \\
\text { lização da terra e dos recursos naturais pelos } \\
\text { seus proprietários } \\
\text { 3. Público ou privado } \\
\text { 4. Público, com o uso concedido às popula- } \\
\text { ções extrativistas tradicionais } \\
\text { 5. Privado }\end{array}$} & \multicolumn{13}{|c|}{$\begin{array}{l}\text { Atividades Possíveis na UC } \\
\text { 1. Visitação pública proibida, exceto com objetivo educacional } \\
\text { 2. Pesquisa científica, com autorizações e restrições } \\
\text { 3. Restauração ou recuperação de ecossistemas modificados } \\
\text { 4. Manejo de espécies para preservação da diversidade } \\
\text { biológica } \\
\text { 5. Coleta de componentes dos ecossistemas, com finalidades } \\
\text { científicas } \\
\text { 6. Visitação pública regulada por normas } \\
\text { 7. Educação e interpretação ambiental } \\
\text { 8. Recreação em contato com a natureza e o turismo ecológico } \\
\text { 9. Utilização, compatível com os objetivos da Unidade, dos } \\
\text { recursos naturais pelos proprietários } \\
\text { 10. Utilização da propriedade privada de acordo com as res- } \\
\text { trições específicas. } \\
\text { 11. Exploração dos recursos naturais em bases sustentáveis } \\
\text { 12. Permanência das populações locais que habitam a } \\
\text { Unidade }\end{array}$} \\
\hline
\end{tabular}

Fonte: Sistema Nacional de Unidades de Conservação (2000). Dados organizados pelo autor.

A justificativa para o PL652/2009 é que o tombamento da serra realizado pelo CONDEPHAAT e a sua inclusão como zona de proteção das APAs CCJ foram incapazes de conter o desmatamento, a ocupação desordenada e a caça. $\mathrm{O}$ art. $2^{\circ}$ do projeto de lei enfatiza que o a criação do parque Estadual da Serra do Japi visa conciliar a proteção integral da flora, da fauna, dos recursos e belezas naturais bem como contribuir para a amenização climática, a recarga natural do lençol freático e a redução da erosão na região. 
A partir das observações do quadro abaixo (quadro 1), observa-se que por ser tratar de uma futura Unidade de Proteção Integral, ficará vedada a presença humana dentro dos limites do parque Estadual da Serra do Japi. Dessa forma, os principais usos seriam para fins educacionais, científicos, recreativos e de turismo ecológico. A proibição da permanência de populações humanas se estenderia aos sitiantes, chacareiros e pequenos produtores rurais que residem nas áreas delimitadas do parque Estadual. O PL 652/2009 é claro ao considerar que a existência da propriedade privada torna difícil a fiscalização contra o desmatamento e a ocupação desordenada, e, assim, a criação de um parque estadual seria a condição inevitável para frear todas as formas de pressão sobre a biodiversidade e os recursos naturais (água) do Japi.

\section{3. ÁREAS DE PROTEÇÃO AMBIENTAL CABREÚVA, CAJAMAR E JUNDIAÍ: CARACTERÍSITCAS TERRITORIAIS E JURÍDICO-INSTITUCIONAIS}

As APAs Cabreúva, Cajamar e Jundiaí (APAs CCJ) são três unidades de conservação contíguas criadas por leis estaduais no ano de 1984.

Quadro 2 - Dados gerais das APAs Cabreúva, Cajamar e Jundiaí

\begin{tabular}{|l|l|l|l|l|}
\hline APA & $\begin{array}{l}\text { Municípios } \\
\text { abrangidos }\end{array}$ & UGRHI & $\begin{array}{l}\text { Área (ha) } \\
\text { Área total (ha) }\end{array}$ & Instrumentos legais de criação \\
\hline Cabreúva & $\begin{array}{l}\text { Cabreúva, } \\
\text { Indaiatuba, Itu } \\
\text { e Salto }\end{array}$ & $\begin{array}{l}10-\text { Médio Tietê/ } \\
\text { Sorocaba }\end{array}$ & 37.197 & Lei estadual n. 4.023, de 22/05/1984 \\
\hline Cajamar & Cajamar & 6 - Alto Tietê & 13.309 & Lei estadual n. 4.055, de 04/06/1984 \\
\hline Jundiaí & $\begin{array}{l}\text { Jundiaí, } \\
\text { Itupeva, Jarinu } \\
\text { e Campo } \\
\text { Limpo Paulista }\end{array}$ & $\begin{array}{l}\text { 5 - Piracicaba/ } \\
\text { Capivari/ Jundiaí }\end{array}$ & 49.329 & Lei estadual n. 4.095, de 11/06/1984 \\
\hline Total & & & 99.835 & \\
\hline
\end{tabular}

Fonte: Fundação Florestal, 2010. Dados organizados pelo autor. 
As três APAs estão localizadas entre nove municípios paulistas, bem próximas às Regiões Metropolitanas de Campinas e de São Paulo. É uma extensa área formada pelos municípios de Cabreúva, Cajamar e Jundiaí e trechos de Campo Limpo Paulista, Indaiatuba, Itu, Itupeva, Jarinu e Salto.

A criação destas unidades teve como objetivo principal a proteção da diversidade biológica e dos recursos hídricos de um maciço montanhoso localizado na região de Jundiaí (formado pelas serras do Japi, Guaxatuba, Guaxinduva e dos Cristais).

Do ponto de vista jurídico-institucional, a regulamentação das APAs foi feita por um único decreto estadual, estabelecendo o gerenciamento participativo e integrado por um conselho gestor.

\section{CONSELHO GESTOR DAS APAS CABREÚVA, CAJAMAR E JUNDIAÍ: ATORES, SINERGIAS E TENSÕES}

Após a edição da lei do Sistema Nacional de Unidades de Conservação, os conselhos gestores das APAs paulistas passaram a apresentar caráter consultivo e composição paritária entre os órgãos públicos (25\% de representantes do Estado e $25 \%$ de representantes dos municípios) e a outra metade composta por entidades de representação da sociedade civil ${ }^{1}$.

Com o aumento da área das APAs CCJ em 2006 houve um entendimento por parte da Secretaria Estadual do Meio Ambienta (SMA) de que seria importante ampliar o número de assentos no conselho gestor a fim acomodar as novas demandas sociopolíticas e conflitos. Os assentos da sociedade civil tiveram um acréscimo de seis para dez vagas e os do poder público (municipal e estadual) de três para cinco vagas.

Em relação aos conflitos presentes nas arenas ambientais, Acselrad (2004) adverte que os interessados no tema devem observar a situação de

1 O mandato do conselheiro é de dois anos, renováveis por igual período, não sendo remunerado, por ser considerado de relevante interesse público. 
vulnerabilidade socioambiental do território a ser investigado. Por isso, entrevistamos os membros do conselho gestor na tentativa de identificar suas percepções acerca de situações de conflitos socioambientais no interior das APAs CCJ. Assim sendo, os temas ambientais identificados como problemáticos pelos conselheiros foram: loteamento e expansão imobiliária (95\%), desmatamento e queimadas (95\%), loteamento irregular (90\%), poluição da água (90\%), atividade mineradora (79\%), escassez da água (74\%), disposição do lixo domiciliar (68\%), saneamento (68\%), uso incorreto dos recursos hídricos (63\%), descarte de desejos da construção civil (63\%), emissões de lixo industrial (58\%).

Cada conselheiro teve a oportunidade, no momento das entrevistas, de apontar quais seriam, em sua opinião, os conflitos mais frequentes entre os agentes atuantes nos perímetros das APAs CCJ. As respostas mais comuns foram: loteamentos oficiais $\mathrm{x}$ conservação dos recursos naturais, atividade mineradora $\mathrm{x}$ conservação dos recursos hídricos/biodiversidade e moradia irregular x legislação ambiental/conservação dos recursos naturais.

Os conselhos gestores de unidades de conservação foram concebidos sob a lógica da resolução de conflitos socioambientais, da "publicização" dos interesses divergentes, da gestão mais eficiente de políticas públicas e do controle social. Devem garantir que as divergências sejam explicitadas por meio de um diálogo qualificado para evitar o acirramento dos conflitos e assim colaborar para a sua resolução.

Compreendemos que um aspecto que pode influenciar positivamente o desempenho dos conselhos é o respeito às diferenças entre os participantes (inclusive as sociais, econômicas e ideológicas). Nesse sentido, os conselhos devem-se constituir em arenas verdadeiramente democráticas e socialmente inclusivas, com a participação de grupos sociais diretamente afetados pelas políticas ambientais: caiçaras, quilombolas, indígenas, povos ribeirinhos, extrativistas, trabalhadores rurais, pequenos proprietários rurais (sitiantes e chacareiros). 
Em relação à satisfação quanto à tomada de decisões no conselho gestor, $68 \%$ demonstraram satisfação e apenas $16 \%$ disseram-se insatisfeitos (ver gráfico 1).

A análise desses números nos permite afirmar que existe uma percepção quanto ao caráter democrático do conselho.

Gráfico 1 - Satisfação do conselheiro quanto à tomada de decisões no conselho gestor

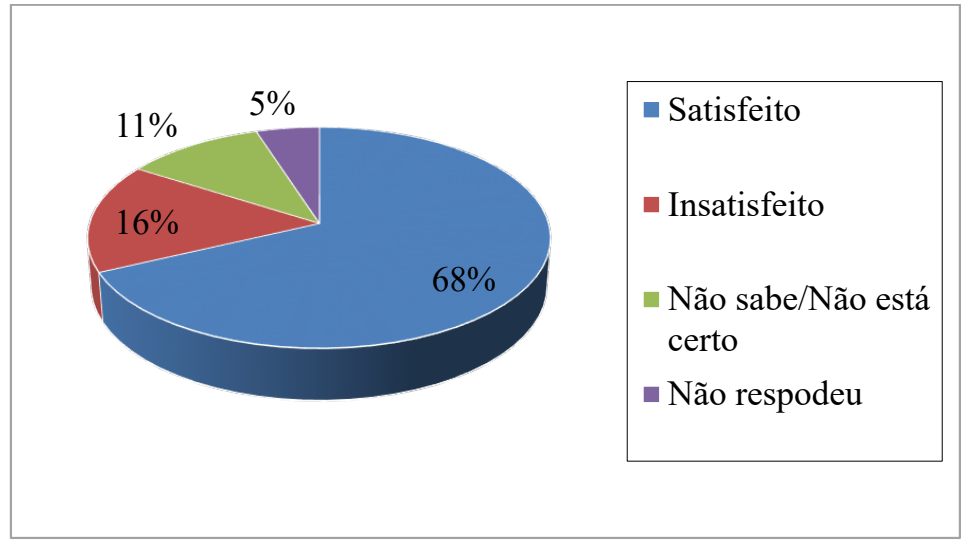

Fonte: ORLANDO, 2010.

Ao analisarmos a qualidade da representação no interior do conselho gestor, a principal crítica se referia à representação "inadequada” das prefeituras municipais e órgãos estaduais, notadamente em relação ao absenteísmo. Existe ainda um sentimento de "desprezo do Estado pela gestão de Áreas de Proteção Ambiental", que "o Estado controla a pauta de discussão" e que "os recursos financeiros são escassos”.

Outro fator que merece atenção é a troca de informações entre os conselheiros e a comunidade local. As informações e resultados positivos da gestão de uma unidade de conservação podem insuflar o processo participativo.

No caso do conselho gestor das APAs CCJ, a circulação das informações internas (relativas ao conselho) é considerada boa: 68\% afirmaram "estar 
satisfeitos”. O problema, segundo os próprios conselheiros, estaria nas trocas de informações entre os próprios segmentos que ocupam assento: $47 \%$ afirmaram que não se sentem informados sobre programas e atividades da sociedade civil, 37\% apontaram desconhecimento sobre programas do Estado, enquanto $68 \%$ não conhecem as atividades desenvolvidas pelas prefeituras.

Não existe uma página eletrônica destinada aos assuntos do conselho, o que poderia facilitar ou tornar mais rápida as trocas de dados entre conselheiros ou mesmo promover o suprimento de informações a respeito do andamento do trabalho do colegiado para o público externo - inclusive para contribuir com a população, revelando-lhe o significado e os objetivos corretos de uma Área de Proteção Ambiental, erroneamente interpretada como "inimiga" do desenvolvimento econômico local ou como unidade de conservação ineficaz.

Ponderando sobre a importância dos conselhos para a resolução de conflitos socioambientais, entrevistamos os conselheiros das APAs CCJ no intuito de saber o que eles pensavam sobre a relação conselho/resolução de conflitos. Para 42\% dos membros, o conselho gestor em questão contribui na "maioria das vezes" para a solução dos conflitos ambientais. Para outros 31\%, o conselho contribui "pouco" e 11\% afirmaram que "nunca".

Nas instâncias do conselho, os maiores conflitos se dão entre segmentos sociedade civil/prefeituras (42\%); $21 \%$ não souberam afirmar entre quais segmentos existiam conflitos.

A resolução dos conflitos no conselho ocorre após consenso com auxílio de mediador para 47\%. Entretanto, 37\% dos conselheiros afirmaram desconhecer a maneira pela qual os conflitos são resolvidos (ver gráfico 2). 
Gráfico 2 - Maneira pela qual os conflitos internos são resolvidos pelo conselho

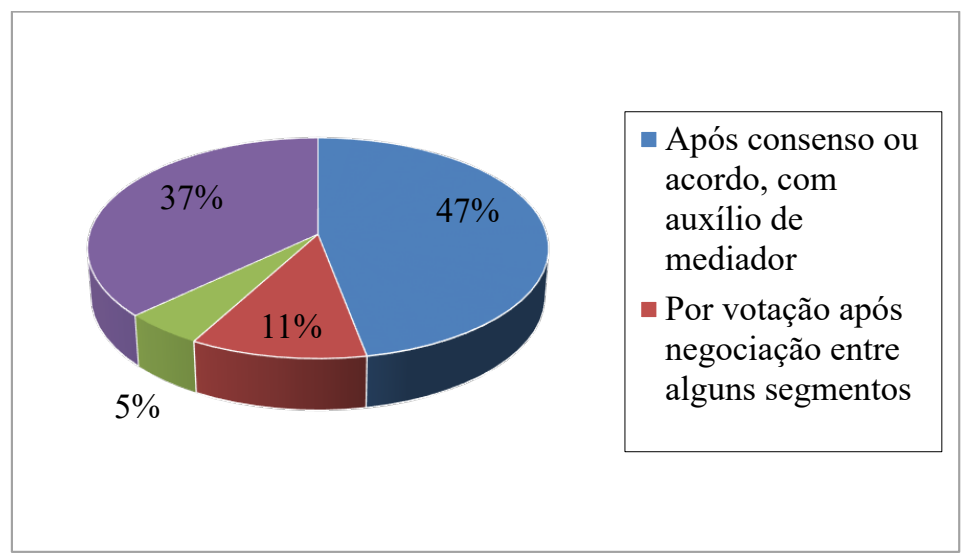

Fonte: ORLANDO, 2010.

O grau de satisfação sobre como os conflitos são resolvidos no conselho é da ordem de $37 \%$. Insatisfeitos totalizam $10 \%$ e não souberam responder $47 \%$. Parece-nos que a dúvida de quase metade dos entrevistados sobre a capacidade do conselho em resolver os conflitos ambientais tem relação com o aparente descaso dos órgãos estaduais: o maior número de respostas (37\%) apontou como principal obstáculo a falta de apoio do governo do Estado. Dificuldades como falta de infraestrutura, falta de conhecimento e informação por parte dos membros, ausência da participação da comunidade local e conflitos exacerbados entre os segmentos representativos receberam $26 \%$ das respostas cada um.

Para alguns representantes da sociedade civil o conselho gestor das APAs Cabreúva, Cajamar e Jundiaí se tornou um mero instrumento legitimador dos interesses da Secretaria Estadual do Meio Ambiente que, por sua vez, é pressionada por forças e interesses do mercado imobiliário e de extração mineral.

No conselho gestor das APAs CCJ, nenhum dos agentes apontou que o nível de confiança entre as pessoas diminuiu nos últimos anos de existência do arranjo institucional. Para 26\%, esse nível aumentou e outros 58\% acreditam que continuou o mesmo (ver gráfico 3). 
Gráfico 3 - Percepção quanto ao nível de confiança durante a gestão do conselho

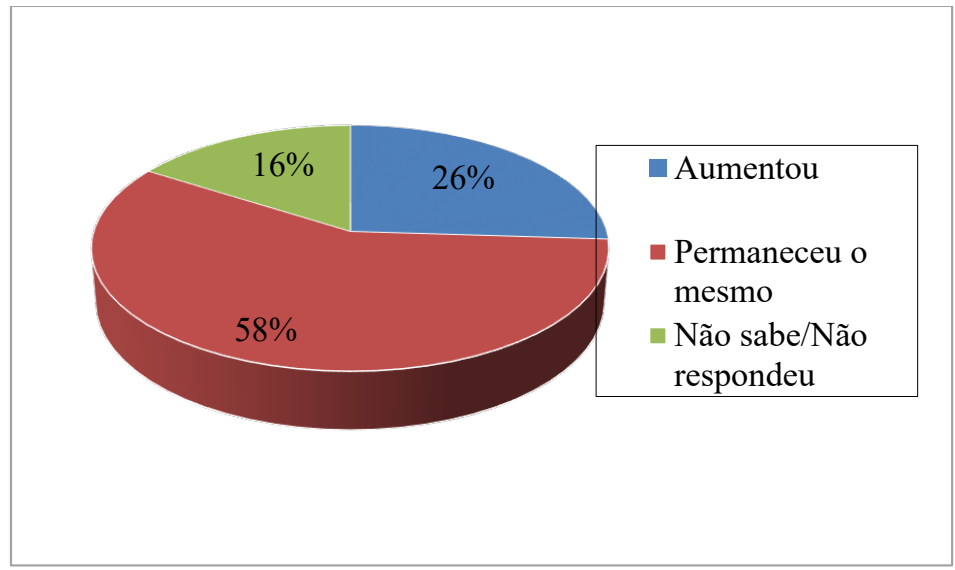

Fonte: ORLANDO, 2010.

Nos conselhos gestores os conflitos e as expectativas dos diferentes atores são "publicizados" para que, por meio da negociação, encontrem-se soluções que atendam ao maior número das expectativas. O desempenho do conselho gestor estaria diretamente relacionado à participação e ao envolvimento dos seus membros.

Para $42 \%$ dos conselheiros, a situação do nível de confiança entre os membros é consequência da pouca interação entre as pessoas. Em algumas entrevistas, apontou-se o absenteísmo dos representantes do Estado e das prefeituras como um dos problemas que afetaria o desempenho do conselho gestor. Para alguns dos entrevistados, o nível de confiança entre os conselheiros possui correlação com a mudança de órgão gestor das APAs (que, pelo menos em um momento inicial, gerou surpresa e desconfiança entre os conselheiros), domínio das pautas das plenárias pelos representantes do Estado, baixo envolvimento de alguns membros, absenteísmo dos representantes do Estado e representação inadequada das prefeituras.

Apesar do conselho não ter tido o êxito de aumentar a confiança entre seus membros, a maioria dos conselheiros (58\%) mostrou-se otimista 
quanto ao seu desempenho. Apenas $26 \%$ mostraram-se pessimistas e outros $16 \%$ não souberam ou não responderam (ver gráfico 4 ).

Gráfico 4 - Grau de confiança no desempenho do conselho gestor das APAs CCJ

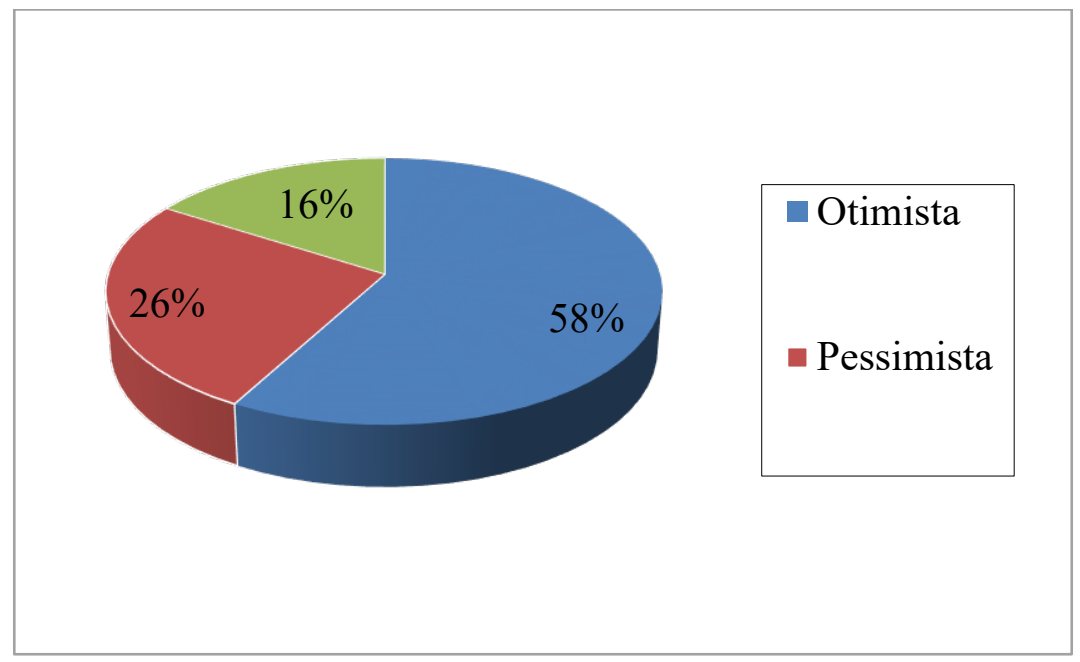

Fonte: ORLANDO, 2010.

Os dados apresentados evidenciam que o conselho gestor das APAs Cabreúva, Cajamar e Jundiaí reproduz as limitações tão comuns a outros arranjos participativos existentes no Brasil. Apesar disso, Gohn (2001) alerta que os conselhos gestores de políticas públicas desempenham um papel pedagógico sobre as práticas participativas implantadas no país apesar das desigualdades sociais, econômicas, culturais e educacionais existentes.

\section{CONSIDERAÇÕES FINAIS}

Localizada entre as regiões metropolitanas de São Paulo e de Campinas, a Serra do Japi transformou-se em um oásis da biodiversidade em 
um espaço profundamente transformado pela produção industrial e urbanização. A heterogeneidade da cobertura vegetal das áreas ainda preservadas, a incrível existência da floresta sobre solos quartzíticos e acidificados e os inúmeros córregos e riachos (úteis ao abastecimento público) que descem pelo relevo acidentado tornam o espaço estratégico para fins de preservação e conservação.

O tombamento da Serra pelo Conselho de Defesa do Patrimônio Histórico, Arqueológico, Artístico e Turístico do Estado de São Paulo (1983) e a criação das Áreas de Proteção Ambiental Cabreúva, Cajamar e Jundiaí (1984) ocorreram após forte mobilização da sociedade contra a expansão urbana acelerada próxima à Serra do Japi. A mobilização em defesa do Japi, organizada por diversas lideranças locais e regionais, pressionou o governo estadual para o atendimento de algumas demandas: constituição de normas e leis específicas para a ocupação e uso sustentável do território.

Entre o tombamento e a criação das APAs até a formação de um conselho gestor (com a participação dos atores sociais) se passou mais de uma década. E tentando acolher a proposta de se tornar um arranjo participativo plural - a fim de acomodar as diferentes expectativas -, o conselho gestor acabou perdendo um pouco a sinergia que amalgamava os diferentes grupos sociais que se dedicaram ao projeto político de proteção ambiental da Serra do Japi.

No caso específico das APAs Cabreúva, Cajamar e Jundiaí, é inegável que a constituição do conselho gestor contribuiu para a democratização da gestão e planejamento do território. Segundo os conselheiros entrevistados, o arranjo permitiu um maior diálogo entre os diferentes setores da sociedade civil e órgãos governamentais (municipais e estaduais).

Durante as entrevistas, a maioria dos conselheiros demonstrou uma satisfação em relação à forma pela qual as decisões são tomadas pelo conselho. Existe uma sensação de que o diálogo e a cooperação influenciam positivamente o gerenciamento das APAs. 
Por outro lado, há uma percepção de que o conselho gestor reproduz as deficiências de outras arenas participativas de unidades de conservação: a informação entre os conselheiros é precária e praticamente não existe um canal de informação das atividades executadas nas APAs com a comunidade local (muito menos um projeto de educação ambiental). Além disso, os conselheiros apontaram alguns entraves para a resolução dos conflitos socioambientais e um entendimento de que o Estado controla a pauta das reuniões, não valorizando a gestão compartilhada das Áreas de Proteção Ambiental.

Tal percepção motivou setores do ambientalismo regional para reivindicação da criação de um parque estadual nas áreas tombadas do Japi. Esta vontade política foi materializada pela entrada de um projeto de lei no ano de 2009 na Assembleia Legislativa de São Paulo. De autoria do ex-deputado estadual e ex-prefeito de Jundiaí, Pedro Bigardi, o projeto de lei tem como justificativa para criação do parque Estadual da Serra do Japi evitar a expansão urbana sobre a área tombada e a zona de proteção máxima das APAs CCJ. Em seu artigo $2^{\circ}$, o projeto de lei defende a proteção integral da flora, da fauna, dos recursos e belezas naturais bem como contribuir para a amenização climática, a recarga natural do lençol freático e a redução da erosão na região.

Por se tratar de uma Unidade de Proteção Integral, no parque Estadual da Serra do Japi ficará vedada a presença humana assim como atividades econômicas. Dessa forma, os principais usos seriam para fins educacionais, científicos, recreativos e de turismo ecológico. A proibição de populações humanas se estenderia aos sitiantes, chacareiros e pequenos produtores rurais que residem nas áreas delimitadas do parque Estadual - daí a advertência de Diegues (2008) ao considerar a problemática regularização fundiária e de indenizações em parques (federias, estaduais e municipais) situados em diversas regiões do Brasil.

O projeto de lei é conclusivo ao considerar que a existência da propriedade privada nas áreas do Japi torna difícil a fiscalização contra o desmatamento, as queimadas e a ocupação desordenada. Sendo assim, segundo o documento, a criação de um parque estadual é condição inevitável para frear 
todas as formas de pressão sobre o Japi e adjacências. No entanto, na tramitação do projeto de lei não foi considerada a melhoria e a busca de maior eficiência dos instrumentos jurídicos já existentes, muito menos as contradições e confusões causadas pela sobreposição de duas ou mais unidades de conservação em uma região.

\section{REFERÊNCIAS BIBLIOGRÁFICAS}

AB’SÁBER, Aziz Nacib. Os Domínios de Natureza no Brasil. São Paulo: Ateliê Editorial, 2012.

ACSELRAD, Henri. (org.). Conflitos ambientais no Brasil. Rio de Janeiro: Relume Dumará: Fundação Heinrich Böll, 2004.

BENSUSAN, Nurit. Conservação da biodiversidade em áreas protegidas. Rio de Janeiro: Editora FGV, 2006.

BRASIL. Lei federal n. 6.902/1981. Dispôs sobre Estações Ecológicas e Áreas de Proteção Ambiental. Disponível em: < http://www2.camara.leg.br >. Acesso em: 10 out. 2018.

. Lei federal n. 6.938/1981. Dispôs sobre a Política Nacional do Meio Ambiente, seus fins e mecanismos de formulação e aplicação, e dá outras providências. Disponível em: < http://www2.camara.leg.br>. Acesso em: 26 abril 2020.

. Lei federal n. 9.985/2000. Institui o Sistema Nacional de Unidades de Conservação - SNUC. Disponível em: <http://www.planalto.gov.br>. Acesso em: 10 out. 2018.

CONSELHO DE DEFESA DO PATRIMÔNIO HISTÓRICO, ARQUEOLÓGICO, ARTÍSTICO E TURÍSTICO DE SÃO PAULO. Resolução no 11/1983. Disponível em: http://condephaat.sp.gov.br. Acesso em 10/08/2020. 
CONSELHO NACIONAL DO MEIO AMBIENTE: Resolução nº 10/1988. Disponível em: http://www2.mma.gov.br/port/conama>. Acesso em $10 / 10 / 2018$.

DIEGUES, Antônio C. O mito moderno da natureza intocada. São Paulo: Hucitec, 2008.

FERREIRA, Marcus B. M.; SALLES, Alexandre O. T. Política Ambiental Brasileira: análise histórico-institucionalista das principais abordagens estratégicas. Revista de Economia. v.43, pp. 17-34, 2016.

GOHN, Maria da G. Conselhos gestores e participação sociopolítica. São Paulo: Cortez, 2001.

MEDEIROS, Rodrigo. Evolução das tipologias e categoriais de áreas protegidas no Brasil. Ambiente \& Sociedade. v. 9, pp. 41-64, 2006.

MERCADANTE, Maurício. Uma década de debate e negociação: a história da elaboração da lei do SNUC. In: BENJAMIN, A. (org.). Direito Ambiental das Áreas Protegidas. Rio de Janeiro: Editora Forense Universitária, 2001.

NEDER, Ricardo de T. Crise socioambiental: Estado \& Sociedade no Brasil (1982-1998). São Paulo: Annablume, Fapesp, 2002.

ORLANDO, Ricardo S. A gestão compartilhada em Áreas de Proteção Ambiental: a experiência do conselho gestor das APA Cabreúva, Cajamar e Jundiaí (SP). Tese (Doutorado em Sociologia) - Universidade Estadual Paulista/Campus de Araraquara, Araraquara, 2010.

PECCATIELLO, Ana Flávia O. Políticas públicas ambientais no Brasil: da administração dos recursos naturais (1930) à criação do Sistema Nacional de Unidades de Conversação (2000). Desenvolvimento e Meio Ambiente. v. 24, pp. 71-82, 2011.

SÃO PAULO. Decreto estadual n. 48.149/2003. Dispôs sobre a criação e funcionamento dos Conselhos Gestores das Áreas de Proteção Ambiental (APAS) 
nos Estado de São Paulo. Disponível em: <https://al.sp.gov.br>. Acesso em: 10 out. 2018.

. Projeto de lei n. 652, de 18 de agosto de 2009. Dispõe sobre a criação do parque Estadual da Serra do Japi. Disponível em: <https://al.sp.gov.br $>$. Acesso em 10/04/2019. 